\title{
Acute arterial ischemia in COVID-19
}

\section{Isquemia arterial aguda em pacientes com COVID-19}

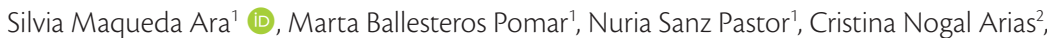
Marcos Del Barrio Fernández ${ }^{1}$

\begin{abstract}
Since the coronavirus pandemic set in in Spain in March 2020, a noteworthy increase in the incidence of acute limb ischemia (ALI) has been observed. It has been recently discovered that SARS-CoV 2 may lead to ALI secondary to arterial thrombosis. Elevation of D-dimer (DD) in patients with coronavirus infection (COVID-19) indicates that a hypercoagulable state causes acute arterial thrombosis. A remarkably high DD elevation has been reported to be a poor prognosis factor in COVID-19. The ways in which SARS-CoV 2 results in arterial thrombosis may be multiple. On the other hand, surgical revascularization for ALI is associated with poor outcomes in COVID-19 patients, probably in relation to hypercoagulability. Here, we describe two ALI cases in patients who required urgent surgical treatment for limb salvage and were positive for the novel coronavirus infection (COVID 19).
\end{abstract}

Keywords: COVID-19; ischemia; thrombosis.

\section{Resumo}

Desde que a pandemia pelo novo coronavírus se estabeleceu na Espanha, em março de 2020, um aumento notável da incidência de isquemia aguda de membros foi observado. Recentemente, descobriu-se que o coronavírus 2 causador da síndrome respiratória aguda grave (SARS-CoV-2) pode ocasionar isquemia aguda de membros secundária à trombose arterial. A elevação do D-dímero em pacientes acometidos pela doença do novo coronavírus (COVID-19) indica o estado de hipercoagulabilidade como causa da trombose arterial aguda. Vale destacar que a alta elevação do D-dímero foi relatada como um fator de prognóstico reservado na COVID-19. Há diversas maneiras pelas quais o SARSCoV-2 pode resultar em trombose arterial. Em pacientes com COVID-19, a revascularização cirúrgica para isquemia aguda de membros está associada a desfechos desfavoráveis, provavelmente relacionados a hipercoagulabilidade. Descrevemos dois casos de isquemia aguda de membros de pacientes que necessitaram de tratamento cirúrgico de urgência para salvamento de membro e que haviam testado positivo para COVID-19.

Palavras-chave: COVID-19; isquemia; trombose.

How to cite: Maqueda Ara S, Ballesteros Pomar M, Sanz Pastor N, Nogal Arias C, Del Barrio Fernández M. Acute arterial ischemia in COVID-19. J Vasc Bras. 2021;20:e20210022. https://doi.org/10.1590/1677-5449.210022

\footnotetext{
${ }^{1}$ Complejo Asistencial Universitario de León - CAULE, León, España.

${ }^{2}$ Universidad de Madrid, Madrid, España.

Financial support: None.

Conflicts of interest: No conflicts of interest declared concerning the publication of this article.

Submitted: January 28, 2021. Accepted: March 13, 2021.
}

The study was carried out at Complejo Asistencial Universitario de León (CAULE), León, España. 


\section{INTRODUCTION}

Since the coronavirus pandemic set in in Spain in March 2020, a significant increase in the incidence of acute limb ischemia (ALI) has been observed. Here, we describe two ALI cases in patients with coronavirus infection (COVID-19).

\section{PATIENT 1}

\section{Clinical situation}

A 70-year-old woman presented to the emergency department with right lower limb pain and coldness for 3 days. The pain developed suddenly without associated trauma and became worse over time. No history of cough, fatigue or dyspnea was elicited; however, she had presented fever 9 days previously.

She had a medical history of diabetes mellitus and hyperlipidemia.

The patient was afebrile and in no respiratory distress; pulse oximetry of $94 \%$ on $4 \mathrm{~L}$ of oxygen. The right leg looked pale from the level of the knee. There was loss of touch sensation in the foot and she had difficulty moving the leg. All right lower extremity pulses were absent. There were no arterial Doppler signals. Pulses in the left leg were normal.

Laboratory results are summarized in Table 1. They included leukocytosis (white blood cell count of

Table 1. Laboratory findings of COVID patients.

\begin{tabular}{lcc}
\hline \multicolumn{1}{c}{ LABORATORY FINDINGS } & Patient 1 & Patient 2 \\
\hline White-cell count (per mm m $^{3}$ & 28800 & 9200 \\
Neutrophils (\%) & $81 \%$ & $88 \%$ \\
Lymphocytes (\%) & $9 \%$ & $8.7 \%$ \\
Monocytes (\%) & $7 \%$ & $3.2 \%$ \\
Platelet count (per mm ${ }^{3}$ ) & 382000 & 221000 \\
Hemoglobin (g/liter) & 12.3 & 14.5 \\
Prothrombin time (PT) (sec) & 15.2 & 21 \\
Activated partial-thromboplastin & 28.2 & 29.8 \\
time (APTT) (sec) & & \\
Aspartate aminotransferase (AST) & 231 & 54 \\
(U/liter) & & \\
Alanine aminotransferase (ALT) & 149 & 25 \\
(U/liter) & & \\
Creatinine (mg/dL) & 2.38 & 0.74 \\
Creatine kinase (U/liter) & 11427 & 329 \\
Lactate dehydrogenase (U/liter) & 669 & 869 \\
Fibrinogen (mg/dL) & 642 & 767 \\
D-dimer (ng/mL) & 72016 & $245196^{*}$ \\
High-sensitivity C-reactive protein & 98.2 & 393 \\
(CRP) (mg/dL) & & \\
Serum ferritin (ng/mL) & 623 & 674 \\
IL-6 (pg/mL) & - & 29.4 \\
\hline
\end{tabular}

$28,800)$ and elevated fibrinogen levels $(642 \mathrm{mg} / \mathrm{dL})$. D-dimer (DD) was markedly increased $(72,016 \mathrm{ng} / \mathrm{ml})$. Other results included Creatinine: $2.38 \mathrm{mg} / \mathrm{DL}$; aspartate aminotransferase (AST): $231 \mathrm{U} / \mathrm{L}$ and alanine aminotransferase (ALT): 149U/L; creatinine kinase (CK): 11,427 IU/L; lactate dehydrogenase (LDH):669 IU/L; and C-reactive protein (CRP): $98.2 \mathrm{mg} / \mathrm{l}$.

Computed tomography (CT) of the chest showed ground-glass opacity and pulmonary infiltration.

The patient's angio-CT scan demonstrated mural aortic thrombus at the infrarenal abdominal aorta as well as thrombotic occlusion of the right iliac artery and infrapopliteal vessels (Figures 1 and 2).

A COVID-19 nucleic acid detection test was negative.

\section{What was done}

The patient was taken to the operating room and underwent a femoral thrombectomy. By means of a Fogarty embolectomy catheter (Le Maitre ${ }^{\circledR}$; Burlington, MA, USA), an extensive thrombus was

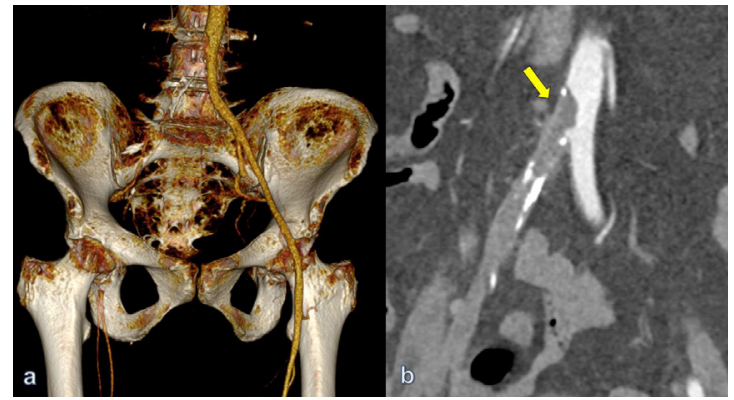

Figure 1. Preoperative computed tomography angiography (angio $\mathrm{CT}$ ) with volume rendering $3 \mathrm{D}$ reconstruction: thrombotic occlusion of the right common and external iliac arteries with patent right femoral bifurcation. Of note, healthy and patent left Ilio-femoral axis (a). Iliac intraluminal thrombus protruding into aorta (arrow) (b) (patient \#1).

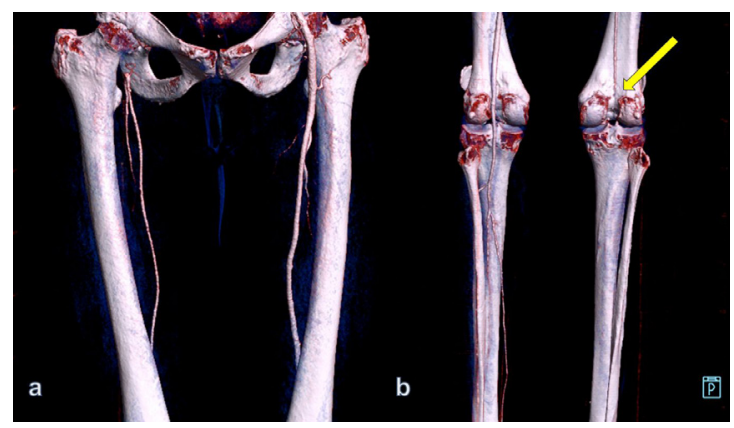

Figure 2. Angio CT with volume rendering 3D reconstruction showing infrafilling of a patent right superficial femoral artery (a). Total occlusion of the right popliteal artery (arrow) with absence of tibial vessels (posterior view). In the left lower extremity, all infrapopliteal vessels are patent (b), (patient \#1). 
retrieved from the iliac artery and femoropopliteal segment. The patient received systemic anticoagulation with subcutaneous enoxaparin sodium at $80 \mathrm{mg}$ once a day. She recovered femoral and popliteal pulses but no distal pulses and several hours later mottled cyanosis appeared at the level of the foot (Figure 3).

Given the irreversible ischemia signs in the foot, a major amputation was carried out 48 hours later.

Serological testing revealed IgG-IgM antibodies to SARS-CoV-2.

\section{PATIENT 2}

\section{Clinical situation}

The patient was a 65 -year-old man, with diabetes mellitus, hyperuricemia, chronic obstructive pulmonary disease, and atrial fibrillation on oral anticoagulant (edoxaban $60 \mathrm{mg}$ once a day). He described a 2-day history of right lower limb pain and coldness.

His physical examination revealed a pale and cool right leg, with dependent distal rubor. He presented femoral pulse with audible arterial Doppler signals at popliteal and distal level. He did not show any impairment of sensitivity or motility.

Duplex scan examination showed occlusion of the right superficial femoral and popliteal arteries.

The patient denied any history of cough, fever, palpitation, or shortness of breath, but chest X-ray revealed peripheral ground-glass lung opacities and multifocal air-space disease (Figure 4a).

Laboratory results on admission are summarized in Table 1. The blood counts showed 9,200 white blood cells ( $88 \%$ neutrophils and $8.7 \%$ lymphocytes).

DD was extremely high (24.5196 ng/ml); CRP: $393 \mathrm{mg} / \mathrm{L}, \mathrm{CK}: 329 \mathrm{IU} / \mathrm{L}$, and LDH: $869 \mathrm{IU} / \mathrm{L}$, all elevated.

The physical examination revealed irregular heart rate (102 beats $/ \mathrm{min})$, blood pressure of $133 / 81 \mathrm{mmHg}$, temperature of $35.9^{\circ} \mathrm{C}$, and oxygen saturation of $91 \%$.

The COVID-19 nucleic acid detection test was negative. The following day, the patient's state became aggravated despite active treatment. His right foot was cold and pale with cyanosis and paresthesia (Figure 4b). The patient noted difficulties in wiggling the toes. His right femoral pulse was faintly palpable and no distal Doppler signals were detected.

\section{What was done}

The patient was taken to the operating room to perform an urgent thrombectomy. Subcutaneous enoxaparin sodium, $1 \mathrm{mg} / \mathrm{kg}$ every 12 hours was started. The clinical condition of the leg improved, but unfortunately the patient died 12 hours later. Serologic testing detected IgG-IgM antibodies to SARS-CoV-2.
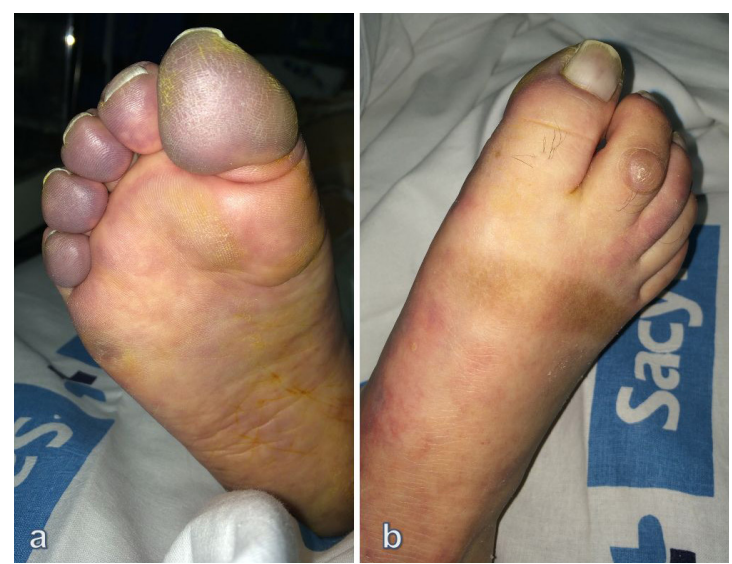

Figure 3. Picture showing patient's foot several hours after revascularization surgery. Digital cyanosis and fixed staining in foot indicate failed revascularization ( $a, b)$ (patient \#1).

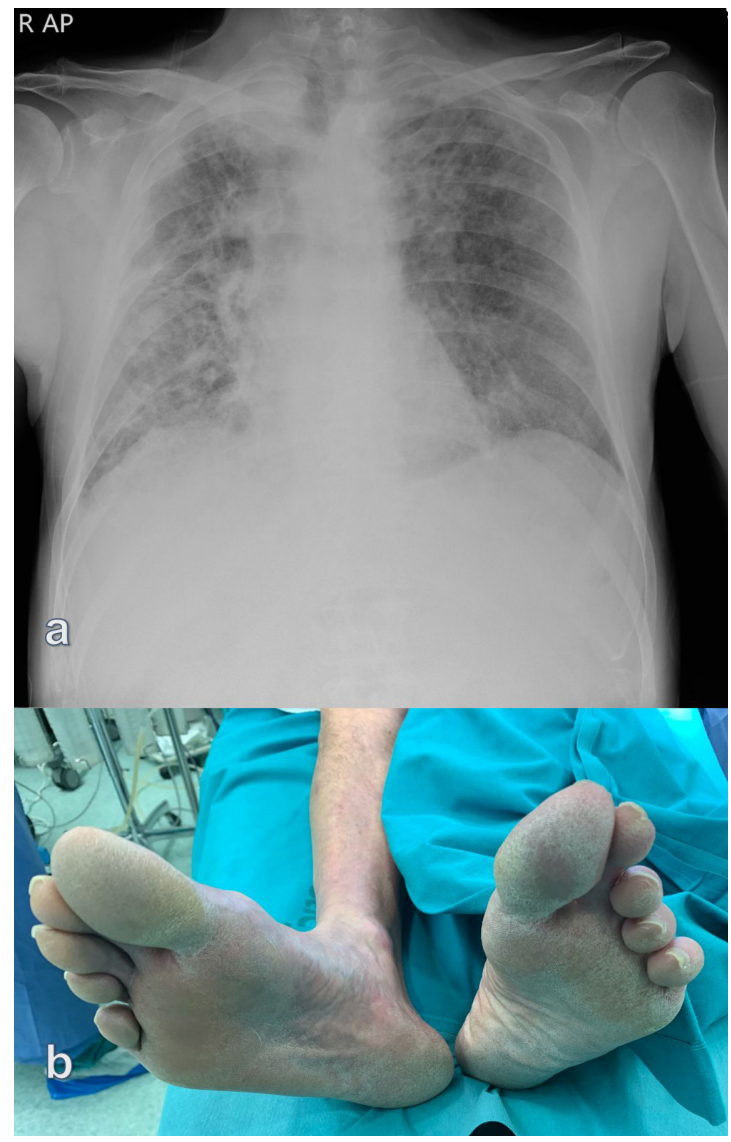

Figure 4. (a) Chest X-ray revealing bilateral peripheral groundglass lung opacities (typical feature of COVID-19 pneumonia) as well as multifocal air-space disease; (b) Preoperative picture showing patient's ischemic foot which required immediate revascularization (patient \#2) 


\section{DISCUSSION}

COVID-19 caused by SARS-CoV-2 has led to a pandemic, infecting over 3 million humans globally and causing over 240,000 deaths by early May of $2020 .{ }^{1}$

In addition to respiratory disease, SARS-CoV 2 infection may lead to thrombotic events. It has been reported that COVID-19 is associated with activation of the coagulation cascade, marked by increased DD levels. ${ }^{1-3}$

Recent guidance on management of coagulopathy in COVID-19 from the International Society of Thrombosis and Haemostasis (ISTH) arbitrarily defined markedly raised DD on admission as a threefold to fourfold increase. ${ }^{1}$ We found high DD values in both patients (higher than reported by others). ${ }^{4-6}$ This information could be useful, especially in patients with a negative COVID 19 nucleic acid detection requiring urgent surgery for ALI.

The ways in which SARS-CoV 2 leads to acute arterial thrombosis may be multiple:

First, virus infections are accompanied by an aggressive pro-inflammatory response and insufficient anti-inflammatory response. This might induce dysfunction of endothelial cells, resulting in excess thrombin generation. ${ }^{1}$

Second, release of pro-inflammatory cytokines, which are key mediators of atherosclerosis, may directly contribute to plaque rupture through local inflammation, induction of procoagulant factors, and hemodynamic changes.

Third, the hypoxia found in severe COVID-19 can increase blood viscosity and the hypoxia-inducible transcription factor-dependent signaling pathway.

Further studies are needed to understand how this new pathology leads to acute arterial thrombosis and if there is a way to prevent it.

\section{ETHICS COMMITTEE}

This study was approved by the institutional research ethics committee. Authors declare that the manuscript is in accordance with the Helsinki Declaration and with local ethical guidelines. Patients were informed and signed informed consent.

\section{REFERENCES}

1. World Health Organization. Coronavirus disease (COVID-19) situation dashboard. 2020 [cited 2020 may 5]. https://www.who. int/emergencies/diseases/novel-coronavirus-2019
2. Zhang L, Yan X, Fan Q, et al. D-dimer levels on admission to predict in-hospital mortality in patients with Covid-19. J Thromb Haemost. 2020;18(6):1324-9. http://dx.doi.org/10.1111/jth.14859. PMid:32306492.

3. Arachchillage DR, Laffan M. Abnormal coagulation parameters are associated with poor prognosis in patients with novel coronavirus pneumonia.J Thromb Haemost. 2020;18(5):1233-4. http://dx.doi. org/10.1111/jth.14820. PMid:32291954.

4. Tang N, Li D, Wang X, Sun Z. Abnormal coagulation parameters are associated with poor prognosis in patients with novel coronavirus pneumonia. J Thromb Haemost. 2020;18(4):844-7. http://dx.doi. org/10.1111/jth.14768. PMid:32073213.

5. Thachil J, Tang N, Gando S, et al. ISTH interim guidance on recognition and management of coagulopathy in COVID-19. J Thromb Haemost. 2020;18(5):1023-6. http://dx.doi.org/10.1111/ jth.14810. PMid:32338827.

6. Wong JP, Viswanathan S, Wang M, Sun LQ, Clark GC, D'Elia RV. Current and future developments in the treatment of virus-induced hypercytokinemia. Future Med Chem. 2017;9(2):169-78. http:// dx.doi.org/10.4155/fmc-2016-0181. PMid:28128003.

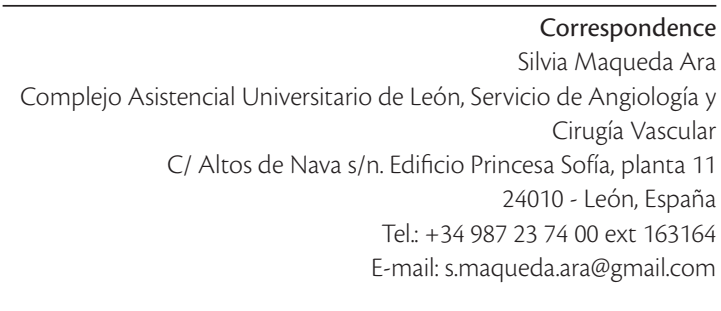

Author information

SMA - Holds a MSc degree in Surgery, Universidad de Zaragoza; PhD, Complejo Asistencial Universitario de León (CAULE). MBP - Holds a MSc degree in Surgery, Universidad de Madrid; PhD, Complejo Asistencial Universitario de León, (CAULE).

NSP - Holds a MSc degree in Surgery, Universidad de Valladolid; PhD, Complejo Asistencial Universitario de León, (CAULE).

CNA - Holds a MSc degree in Surgery, Universidad de Madrid. MDBF - Holds a MSc degree in Surgery, Universidad de Oviedo; PhD, Complejo Asistencial Universitario de León, (CAULE).

Author contributions Conception and design: SMA, MBP, NSP, CNA, MDBF Analysis and interpretation: SMA, MBP, NSP, CNA, MDBF Data collection: SMA, MBP Writing the article: SMA, MBP

Critical revision of the article: SMA, MBP, MDBF Final approval of the article*: SMA, MBP, NSP, CNA, MDBF Statistical analysis: SMA, MBP, NSP, CNA, MDBF Overall responsibility: SMA

${ }^{*}$ All authors have read and approved of the final version of the article submitted to J Vasc Bras. 